\title{
A Role For Universities in Sustaing Regional ICT Initiatives? Exploring the Case of the University Of Ballarat
}

\author{
Helen C. Thompson \\ University of Ballarat $<$ h.thompson@ballarat.edu.au $>$
}

\begin{abstract}
This paper discusses the important support role that universities can play in the establishment and ongoing sustainability of regional information and communication technology (ICT) initiatives. Three case studies are presented to explore the uptake of ICT in a regional and rural context. A common element in each of these initiatives is the active participation of the University of Ballarat throughout all project phases. The resultant combination of on-the-ground leadership, infrastructure, collaboration and multi-disciplinary research has not only created benefits for the individual communities but also through the generation of consultancy income, publications and community engagement of a type which is highly consistent with the University's vision and mission.
\end{abstract}

\section{Introduction}

At the highest level of engagement, universities connect in a strategic, whole-of-institution way by providing an on-the-ground package of leadership, infrastructure, collaboration and multi-disciplinary research and teaching targeted at areas of regionally identified economic development priority that are consistent with campus priorities.

(Garlick 2000, p.xiii)

Information communications technology (ICT) has been identified as a key enabler in the achievement of regional and rural success, particularly in terms of economic and business development. The potential for achieving equity of service through improved communications infrastructure and enhanced access to government, health, education and other services has been identified (Information Policy Advisory Council, 1997). ICT has also been linked to the aspiration of community empowerment where dimensions include revitalising a sense of community, building regional capacity, enhancing democracy and increasing social capital (O'Neil, 2002).

A raft of government policies and programs has been launched and reports published and disseminated, based around the theme of ICT and online capabilities. These are supported by the view that success today is based less and less on natural resource wealth, labour costs and relative exchange rates and more and more on individual knowledge, skills and innovation. But how can regional communities 'grab their share of this wealth' and use it to strengthen local communities (Simpson, 1999, p. 6)? Should communities be moving, as Porter (2001, p. 18) recommends (for business), away from the rhetoric about 'Internet industries', 'e-business strategies' and the 'new economy' to see the Internet for what it is 'an enabling technology - a powerful set of tools that can be used, wisely or unwisely, in almost any industry and as part of almost any strategy'?

Consistent with reflections on international industry experience, there is now a greater emphasis on identifying locally appropriate initiatives, exploring opportunities for improving existing communication and service quality and for using the Internet and ICT to support more efficient community processes and relationships. 
This paper explores the potential role that Universities can play in establishing and sustaining regional information and communication technology (ICT) initiatives. The case of the University of Ballarat (UoB) and its Centre for Electronic Commerce and Communications (CECC) is used to illustrate how one regionally based university has established long-term partnerships to support growth in the uptake and the more effective utilisation of ICT. The author, who manages CECC, then presents three client cases to explore the engagement approach which has been adopted to grow the uptake of ICT in a regional and rural context.

\section{University Region Engagement}

For universities and regional communities, the competitive economic development benefits from engagement revolve around the creation of human capital, social capital and the realisation of employment, investment and income generating economic development priorities within a knowledge creation and transfer framework.

(Garlick, 2000, p.4)

The University of Ballarat is a distinctive, dual-sector regional institution pre-eminently serving the Australian communities of the Central Highlands and Wimmera regions of Victoria. Regional engagement is enshrined in the mission and strategic priorities of University with the overarching vision of being a regional university of international standing, highly regarded by the communities it serves.

While university engagement with regional communities is not a new subject the prospect has become increasingly attractive for both universities and regions with identified benefits going far beyond those traditionally seen as possible (Garlick, 2000).

The challenge however is for universities to effectively support Centres and researchers in actively engaging with regional communities to address community-identified needs, problems and issues and through engagement to generate and apply knowledge that promotes economic, environmental and social prosperity (Institute for Regional and Rural Research, 2003).

At the University of Ballarat, the establishment of the Institute for Regional and Rural Research and its four designated Research Centres during 2002 has been one strategy towards achieving increased university-region engagement. Modifications to reward and recognition systems have also been implemented with community engagement now an explicit component of the School funding model and a performance indicator which academics must report against when seeking promotion.

The identification of key focus areas also assists Schools and Centres in achieving alignment between their activities and the strategic priorities and mission of the University. One such focus is to provide leadership for the uptake of ICT in industries, local government and within and among regional groups (University of Ballarat, 2002).

The School of Business and its Centre for Electronic Commerce and Communications (CECC) contribute to this objective by promoting the advancement of ICT, particularly in its practical application in regional and rural Australia. Since being established in 1998 CECC has built extensive partnerships within and beyond the University region through the development and implementation a range of projects utilising information and communication technologies. The applied nature of CECC activities has generated mutually beneficial outcomes for participant communities and the University with new opportunities for collaboration emerging through engagement activities directed towards the achievement of regionally identified priorities.

Through the implementation of a \$409,000 Federal Government Networking the Nation (NTN) funded regional portal project (www.mainstreet.net.au) during the period between 1999 and 2001, CECC gained an enhanced understanding of regional ICT needs. CECC also established significant capabilities in developing, replicating and customising online services capable of meeting the specific needs of regional communities (Thompson, 2002). Diverse groups and organisations now access services through CECC. These include local governments, town based communities, membership based organisations, industry groups and small and medium enterprises. 
Table 1 summaries some of the major initiatives where CECC has provided an on-the-ground package of leadership, infrastructure, collaboration, multi-disciplinary research and training targeted towards areas of regionally identified priority. Taken as a whole, these activities reflect a high level of community engagement that is very consistent with the strategic priorities of the University.

Information about CECC initiatives has been organised using a modified version of a Taxonomies of Networking framework proposed by Denison et al. (2002). This enables activities to be classified according to a number of major categories of network-related activities, which while not exclusive, have been identified as providing a relatively good fit to observed activities in the Australian ICT scene. Initiative outcomes are then specified using five dimensions identified as key aspirations for ICT engagement. These dimensions are: enhancing strong democracy; increasing social capital; empowering individuals; revitalising a sense of community; and providing economic development opportunities (Denison, Hardy et al., 2002).

\begin{tabular}{|c|c|c|c|c|c|}
\hline \multirow[b]{2}{*}{ Initiative } & \multicolumn{5}{|c|}{ Aspirations for ICT Engagement } \\
\hline & $\begin{array}{l}\text { Enhancing } \\
\text { strong } \\
\text { democracy }\end{array}$ & $\begin{array}{l}\text { Increasing } \\
\text { social capital }\end{array}$ & $\begin{array}{l}\text { Empowering } \\
\text { individuals }\end{array}$ & $\begin{array}{l}\text { Revitalising a } \\
\text { sense of } \\
\text { community }\end{array}$ & $\begin{array}{l}\text { Providing } \\
\text { economic } \\
\text { development } \\
\text { opportunities }\end{array}$ \\
\hline \multicolumn{6}{|c|}{ Collectives of Geographically Based Entities - Cross-Sectoral } \\
\hline $\begin{array}{l}\text { Ballarat - A } \\
\text { Learning City }\end{array}$ & Low & High & High & High & Medium \\
\hline $\begin{array}{l}\text { Wendouree } \\
\text { West } \\
\text { Community } \\
\text { Renewal }\end{array}$ & High & High & High & High & High \\
\hline $\begin{array}{l}\text { Rural Law } \\
\text { Online }\end{array}$ & Medium & Medium & High & Low & High \\
\hline \multicolumn{6}{|c|}{ Civic Networks - Government Agency Led } \\
\hline Ararat Online & Med & High & High & High & High \\
\hline $\begin{array}{l}\text { Moorabool } \\
\text { Online }\end{array}$ & Med & High & High & High & High \\
\hline Pyrenees Online & Low & Low & Low & Low & Low \\
\hline $\begin{array}{l}\text { Young } \\
\text { Australian Rural } \\
\text { Network }\end{array}$ & High & High & High & High & High \\
\hline \multicolumn{6}{|c|}{ Clusters of Like Organisations - Intra-Sectional } \\
\hline $\begin{array}{l}\text { Birchip } \\
\text { Cropping Croup }\end{array}$ & Low & High & High & High & High \\
\hline $\begin{array}{l}\text { Building Better } \\
\text { Business Online }\end{array}$ & Low & High & High & Medium & High \\
\hline $\begin{array}{l}\text { Central } \\
\text { Highlands } \\
\text { Export } \\
\text { Community }\end{array}$ & Low & Medium & Medium & Medium & High \\
\hline $\begin{array}{l}\text { Victorian } \\
\text { Universities } \\
\text { Regional } \\
\text { Research } \\
\text { Network } \\
\end{array}$ & Low & High & High & Medium & Medium \\
\hline \multicolumn{6}{|c|}{ Individual Community Organisations } \\
\hline $\begin{array}{l}\text { Central } \\
\text { Highland ACC }\end{array}$ & Low & Low & Medium & Low & Medium \\
\hline $\begin{array}{l}\text { Regional } \\
\text { Connectivity } \\
\text { Project }\end{array}$ & Low & Medium & Medium & Medium & Low \\
\hline Regional Voice & High & Medium & Medium & Low & Medium \\
\hline
\end{tabular}

Table 1. Outcomes of ICT Engagement 


\section{Demonstrating University-Region Engagement}

This is the issue of whether the university is only in the regional community or more fundamentally of it.

(Garlick 2000, p. 10, emphasis in original)

Findings from evaluation activities confirm that communities accessing services through CECC are being effectively empowered to mange online initiatives to a greater extent in areas such as:

1. Planning - Incorporating aspects such as initial research, project design, user input and community consultation.

2. Scoping technical and project management requirements - Identifying the project stages which can managed locally and those which may need to be outsourced (for example initial development, hosting and ongoing technical support).

3. Evaluation - Setting short and long-term project goals; conducting regular reviews; and maximising usage of statistical and other information such as user feedback.

4. Replication - Applying similar strategies in new community initiatives and projects.

5. Knowledge - Greater understanding of the underlying technologies and human capital requirements for sustaining initiatives.

6. Community engagement - Recognition of the benefits of supporting ongoing user involvement, interaction and active stakeholder engagement.

CECC clients demonstrate strong ownership of their initiatives, maintain their own web-based information and are committed to investing annually to maintain the shared infrastructure and services they access through the University of Ballarat.

The engagement approach utilised by CECC will be explored further through three client case studies. In the first case the community of Wendouree West is utilising web-based services to support place-based renewal activities (a collective of neighbourhood stakeholders). The second case study explores how communities in the Moorabool Shire are gaining access to web-portal services (government agency led civic network). The third case then reviews an initiative where organisations including the Centre for Regional Innovation and Competitiveness, Service Skills Victoria, Tourism Victoria and local tourism bodies are collaborating to enhance the skills of small and micro tourism operators in the Goldfields region of Victoria (cluster of like organisations - intra-sectoral).

\section{Wendouree West Community Skills Survey}

Infrastructure for collaboration consists of the pathways by which people and organisations come together to exchange ideas, solve problems or form partnerships - to recognise, value, and leverage their area's assets for mutual gain.

(Garlick, 2000, p. 11)

The Victorian Government's Neighbourhood Renewal program has been established in a number of Victoria's most disadvantaged neighbourhoods, with the purpose of developing joint government and community-based approaches to address multiple causes of disadvantage. One of the key concerns has been to lift employment, training and education and expand local economies, through the development of community-based employment and education programs.

The progressive rollout of the Neighbourhood Renewal Program commenced during 2001. Since that time, the University of Ballarat, through CECC and Centre for Regional Innovation and Competitiveness (CRIC), has had a significant role in the development, administration and analysis of the Community Survey and the Community Skills Survey. 
During 2002 CECC was engaged by the Department of Human Services (DHS) to support the Wendouree West Community in conducting a local skills survey. The aim was not just to actively involve residents in the collection of information on the skills and learning aspirations of residents but also to make sure the results would be both useful and used.

In implementing the project the University of Ballarat undertook significant awareness raising and consultation activities to actively engage residents and members of the Renewal Team during the planning phase of the project. Once agreement had been reached on the overall project goals and approach CECC was able to commence development of the 'Community Skills Survey Package'. This included: designing and piloting the survey instrument (for distribution via paper-based and web formats); establishing web-based administration facilities for managing resident responses; hosting the survey infrastructure; and providing ongoing advice and support.

Resident volunteers assisting in rollout of the project were provided with training in survey techniques prior to the commencement of the Community Skills Survey during November 2003. Further training was provided to members of the Renewal Team who would be responsible for the initial entry of survey responses and for the ongoing utilisation and management of the web-based facilities.

At the end of the initial survey period a total of 175 completed surveys were returned to the Wendouree West Community Renewal Office. A member of the Renewal Team entered the details of each survey into the web-based system which can be accessed at www.cecc.com.au/communities/wendouree (see Figure 1).

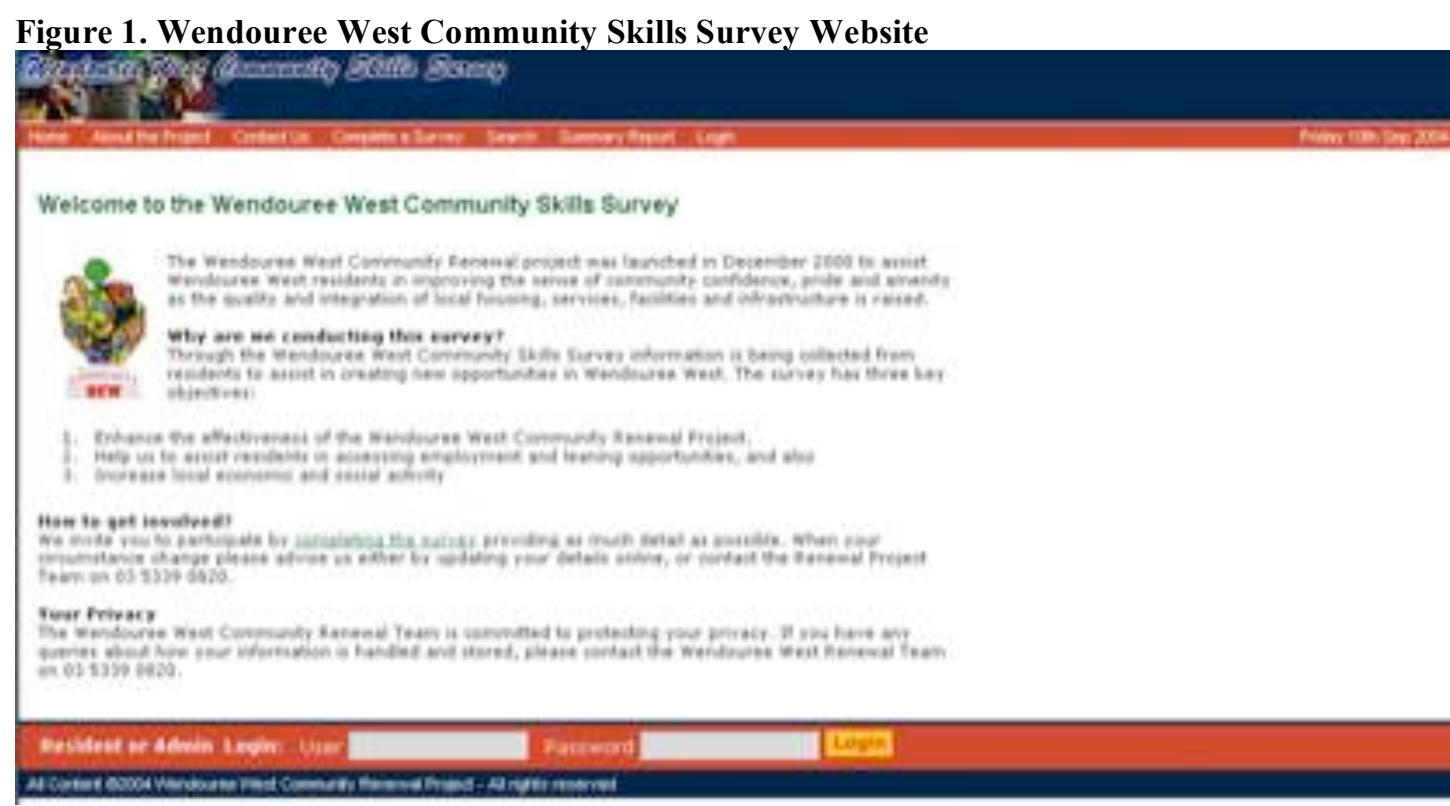

The dynamic reporting capabilities of the system supported the Renewal Team and other key stakeholder in reviewing the characteristics of respondent, for example age, gender dispersion, time lived in Wendouree West, and the level of telephone access. The full report can be accessed at www.cecc.com.au/communities/wendouree by clicking on the Summary Report link.

In an initial evaluation undertaken by CECC during January 2004, the Skills Survey Data was combined with Australian Bureau of Statistics (ABS) census data to evaluate factors such as participation rate (10.26 percent); age profile (most significant response received from residents aged between 45-64 years); and gender (a high participation rate among female residents was confirmed.

The skills survey information provides opportunities for making better use of existing resources and also identifies new resources that can be used to build on the strengths that already exist in Wendouree West. Comprehensive information is, for example, now available on the skills, 
employment and learning aspirations of individual residents with information including those skills they have, could teach or want to learn (see Table 2).

\begin{tabular}{lllll}
\hline Trades and occupations & I have & I can teach to others & I want to learn & Formal qualification \\
\hline Carpentry & 17 & 3 & 11 & 0 \\
Welding & 22 & 3 & 10 & 1 \\
Painting & 52 & 3 & 9 & 2 \\
Electrical & 15 & 1 & 9 & 2 \\
Appliance repair & 16 & 1 & 11 & 1 \\
Other & 23 & 2 & 1 & 4 \\
Plumbing & 12 & 0 & 11 & 0 \\
Gardening & 67 & 6 & 7 & 0 \\
Truck or bus driving & 20 & 0 & 10 & 1 \\
Office work & 27 & 2 & 14 & 4 \\
Retail & 42 & 4 & 4 & 4 \\
Mechanic & 20 & 5 & 9 & 3 \\
Professional & 9 & 0 & 8 & 4 \\
Cleaning/maintenance & 70 & 10 & 3 & 4 \\
\hline
\end{tabular}

Table 2. Summary information skills: Trades and occupations

Residents described the types of connections they have within the community and indicated areas where they wanted further information or to become involved (see Table 3).

\begin{tabular}{ll}
\hline Community Groups & Count \\
\hline I am already involved & 31 \\
I would like to be involved & 10 \\
I would like more information & 27 \\
I do not wish to be involved & 26 \\
\hline
\end{tabular}

Table 3. Summary information connections: Community Groups

Residents also indicated whether they were willing to become more actively involved in the community (see Table 4) and/or share their skills with others.

\begin{tabular}{ll}
\hline Commitment & No of people \\
\hline Meet with and get to know my neighbours and/or others in my & 35 \\
street or community & 34 \\
Help with community clean-ups & 32 \\
Look out for/care for others in my community & 32 \\
Help with Neighbourhood Watch & 18 \\
Become a leader & 26 \\
Be happily 'led' by others
\end{tabular}

Table 4. Summary information commitments: Own community

Through its partnership with the University of Ballarat the Wendouree West community has secured appropriate infrastructure to support the community in recognising, valuing and levering its area's assets to address issues of local priority. This has more effectively supported the development and implementation of community driven strategies to boost employment, education, training, and enterprise development. Early benefits have included:

1. The identification of new skills and resources which can be mobilised in areas such as volunteering and community participation. 
2. The creation of opportunities to actively engage key stakeholder organisations such as job network providers, services groups and learning providers.

3. The development and implementation of strategies to extend community involvement in the Skills Survey beyond the initial levels achieved.

Skills survey information has been utilised to assist residents in accessing employment and learning opportunities and to increase participation and pride in the community. Specific examples include:

1. Matching residents with employment and training opportunities through the Community Jobs Program for Carers.

2. Identifying residents with skills appropriate to the establishment of a Community Enterprise for the fencing and painting services.

3. Identifying residents interested in volunteering to assist with the establishment of a local AusKick program.

4. Personally inviting residents to participate in Community Working Bees, for example, during the redevelopment of Apex Park.

5. Identifying and engaging residents through undertaking skills training to support the establishment of a local Gym.

CECC is now supporting the Wendouree West community with preparations for the second round of community skills surveys. Current participants will be invited to update their details online or via a paper-based survey (with current details included). Volunteer residents will also distribute surveys to those residents who have not yet participated and encourage and support their participation.

While revenues generated through the Wendouree West Community Skills Survey have been relatively low, the community engagement, research and development benefits for the University have been significant. With strong potential for UoB to be engaged to implement a state-wide rollout of the skills survey across all Neighbourhood Renewal areas, financial benefits may now flow from an initiative which was originally supported to ensure that appropriate ICT infrastructure and support services would enhance the success of a significant local initiative.

\section{Moorabool Community Online}

In February 2000 CECC first assisted the Moorabool Shire in attracting funding and implementing a local community portal (www.mconline.com.au). Since this first joint project, the University of Ballarat has continued to provide a range of consultancy and other services to the Moorabool Shire to support the ongoing development and expansion of McOnline. One recent example is a project with the local Arts and Heritage Advisory Committee to establish web-based services for an online register of Council and Historical Society assets (www.mconline.com.au/chad). In this paper the engagement approach, processes and outcomes generated through the Mt Egerton township website project (www.mtegerton.com) are reviewed.

Mt Egerton is located 28 kilometres east of Ballarat and as at the 2001 census recorded a population of 198 representing just 0.9 percent of the resident population for the Moorabool Shire (Australian Bureau of Statistics, 2003). The township developed during the 1850s when gold was discovered in the quartz reef passing through the area. This led to the establishment of significant mining activity in the area with one commercial mining operation still active within the township in 2004. Other town facilities include a local primary school, mixed business, community hall and oval.

The Mt Egerton website initiative commenced after the community secured funding from the Foundation for Rural and Regional Renewal during 2003. The Moorabool Shire recommended that the Mt Egerton website be developed within the McOnline community portal infrastructure (Thompson, 
2004). With support from the Moorabool Shire, CECC was subsequently engaged to assist community members through the planning, development and implementation phases of the project. CECC would also provide web products, hosting and support services and assist in the ongoing evaluation of the project.

MtEgerton.com incorporates similar functionality to McOnline (business and community directories, news, events, web links and resources). Where appropriate content added to MtEgerton.com is also accessible through McOnline (for example local business listings and events). The township website also incorporates some additional features to meet local requirements. These include online classifieds and a games section to engage young people in the community.

The Mt Egerton Community Development Group is responsible for the overall management of MtEgerton.com. This group of mainly senior residents secured the seed funding and assisted in establishing the MtEgerton.com working party which would be responsible for overseeing the development and ongoing maintenance of the township website.

The MtEgerton.com working party comprises approximately 10 active members who are predominately young residents. Each member has taken on specific roles and responsibilities which include project manager, news editor, youth news reporter, digital photographer, event promoter and forum administrator. With the initial development completed members of the MtEgerton.com working party coordinate the publishing of site content, identify local content providers, deliver training and conduct promotional and fundraising activities to support ongoing development and sustainability of the site.

Figure 2 illustrates the MtEgerton.com township website which was designed in consultation with members of the community working group. While the site intentionally incorporates colours and design features which complement McOnline it also provides the Mt Egerton community with its own unique look and identity on the Internet.

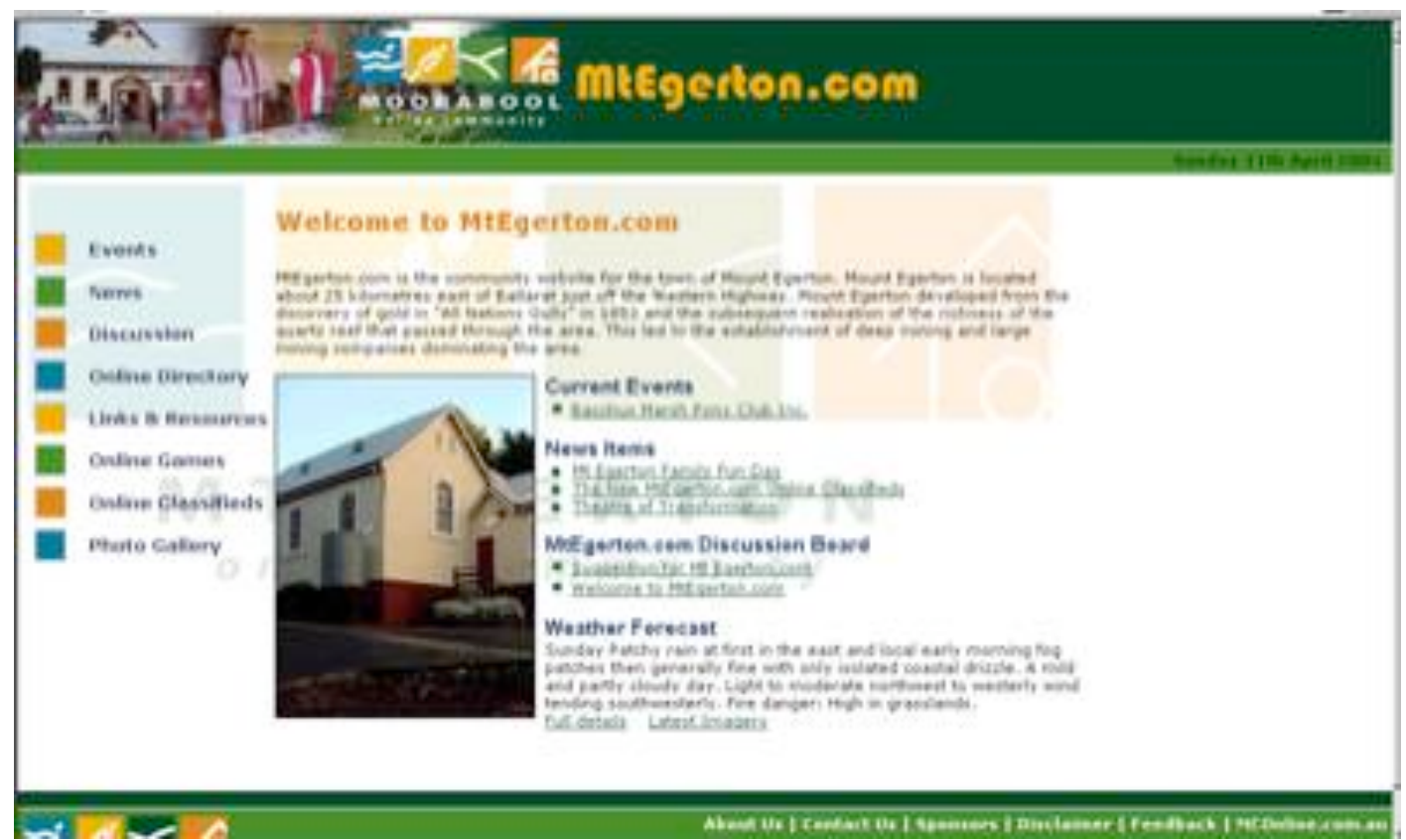

Figure 2. MtEgerton.com

MtEgerton.com was launched during March 2004. In the five-month period to 31 August 2004 the site has received 1,787 visits and recorded 7,288 page views. Site visits have increased to an average of 14 unique visits a day with utilisation particularly as measured visits, generally trending upwards. The areas of highest site utilisation are the games area and home page currently attracting utilisation between a range of 4.18 percent to 25.98 percent of site hits. Utilisation of the events calendar has ranged between 2.02 percent and 9.64 percent. Other site areas which 
include the business/community directory, news, suggestions, links and photograph/gallery section have recorded utilisation within the range of zero to 5.18 percent.

The MtEgerton.com project has generated significant community benefits with the Moorabool Shire effectively supporting Mt Egerton in achieving its goal of establishing its own local website. Senior residents are mentoring and supporting younger residents. Formal and informal training has been undertaken. New linkages are being established within the community and residents are working together in new ways. They are also sharing their skills and experience by working with residents in surrounding towns as they embark on township website projects.

Through the MtEgerton.com project the UoB has developed and documented a model which will support the Moorabool Shire in achieving its objective of supporting local communities in the establishing appropriate and sustainable web-based services that build on and further enhance the McOnline community portal. Online services will now be expanded within a coordinated framework with communities taking responsibility for site development and management and for the ongoing funding of hosting and client support costs. Based on the experience in Mt Egerton the Moorabool Shire has also decided to more closely link the establishment of e-gap Kiosks (internet access points) with township website initiatives in its small communities.

CECC's product suite has been expanded to include the TownBuilder product through the MtEgerton.com project. This will facilitate future replication and customisation of the functionality and make it accessible for the creation of additional township sites for Moorabool Shire and for other regional and rural communities.

If an application for funding to the McPherson Smith Community Alliance program for $\$ 36,500$ funding is successful, the Ballan and District Community Capacity Building Project Steering Committee, the Moorabool Shire, and the University of Ballarat will work in partnership to support between four and six townships with establishing local community websites.

A number of important themes can be drawn from the outcomes generated as a result of the partnership between CECC and the Moorabool Shire over a five-year period:

1. McOnline initiatives have been pursued as part of a clearly articulated strategy with strong links, for example, to traditional marketing methods and established local networks.

2. Initiatives have been developed to support various sectors of the community, for example, the business sector (eCommerce mentoring programme), small towns (internet access points, township websites and local training opportunities), individuals (community building activities linked to regional ICT initiatives through McOnline), and community groups (museums and cultural groups through the CHAD project, other community groups through the McOnline SiteBuilder program).

3. Continued focus on empowering local businesses and individuals through the provision of training and other learning opportunities but also by securing appropriate online services (including ongoing support services) which effectively meet local needs.

4. Strong leadership (particularly from the Corporate Services Manager) and an ongoing commitment from local government to attract funding for related but discrete initiatives and then to ensure that services are sustained beyond any initial seed funded period.

5. Ongoing commitment to involving community members in the development and implementation of online strategies (local working group formed, community representatives trained, review workshops held, targeted initiatives identified and funded, and regular reviews completed). 


\section{Capacity Building For Small And Micro Tourism Operators}

The Building Better Business Online (www.bbbonline.com.au) project has been designed to deliver an innovative ICT enhanced training package to small and micro tourism businesses in the Goldfields Region of Victoria. The project attracted AusIndustry funding of $\$ 145,000$ and significant support from organisations including Service Skills Victoria, Tourism Victoria, Ballarat Tourism and Bendigo Tourism. It is a business skills program based on tourism industry accreditation with the pilot region including the towns of Ballarat, Bendigo, Creswick, Clunes, Castlemaine, Daylesford and Maldon.

In its proposal for AusIndustry funding, the University of Ballarat identified that a lack of tourism business entry barriers and paucity of business skills were key impediments to competitiveness with many small and micro tourism businesses displaying a lack of appreciation for the importance of business training, destination marketing and relationship building (Braun and Hollick, 2002).

Small and micro tourism owners and managers will benefit from a training program that uses ICT for business learning and combines action learning methods to support the sharing of knowledge for best business practice, regional growth and destination marketing. While building skills and creating a culture of lifelong learning are the main program objectives it is anticipated that an increased number of accredited operators will be an outcome of the pilot at its conclusion in July 2005.

A broader project goal is the development of a model, which links in a sustainable way, skills development to better industry performance. It is envisioned that with support from Service Skills Victoria, the centralised learning modules and ICT infrastructure developed through the pilot program will be made available through the Better Business Tourism Accreditation Program to support efficient delivery of subsequent initiatives across regional Victoria (Braun and Hollick, 2002).

CECC was contracted to develop services to underpin the BBBOnline project. Given indications that many tourism operators in the pilot region had only one designated telephone line and a high reliance on dial-up Internet access it was identified that a significant proportion of operators would need work offline. CD-ROM technologies would support participation by a larger number of businesses towards the target of 540 small and micro businesses.

BBB Online offers flexible learning materials in CD-ROM format; in a web-based online learning environment; and through 'how to' workshops. These workshops have been designed to familiarise operators with the learning materials and to teach participants how to access materials via CD-ROM or online.

In the first development phase CECC established a web-presence to support the project team in promoting the BBBOnline initiative (see figure 3). CECC then undertook significant research which was documented in the project design specifications. Exploring all issues related to provision of the learning program via CD-ROM was particularly important. While CECC had experience in producing read-only CD-ROMS the requirement support operators in saving and progressively update information was new.

The task of developing the ICT infrastructure; incorporating the initial learning program materials; integrating participant resources; and establishing communication systems; then commenced. All initial content and updates were published via the web-based application with periodical 'snapshopts' converted to CD-ROM. 


\section{bböonline}

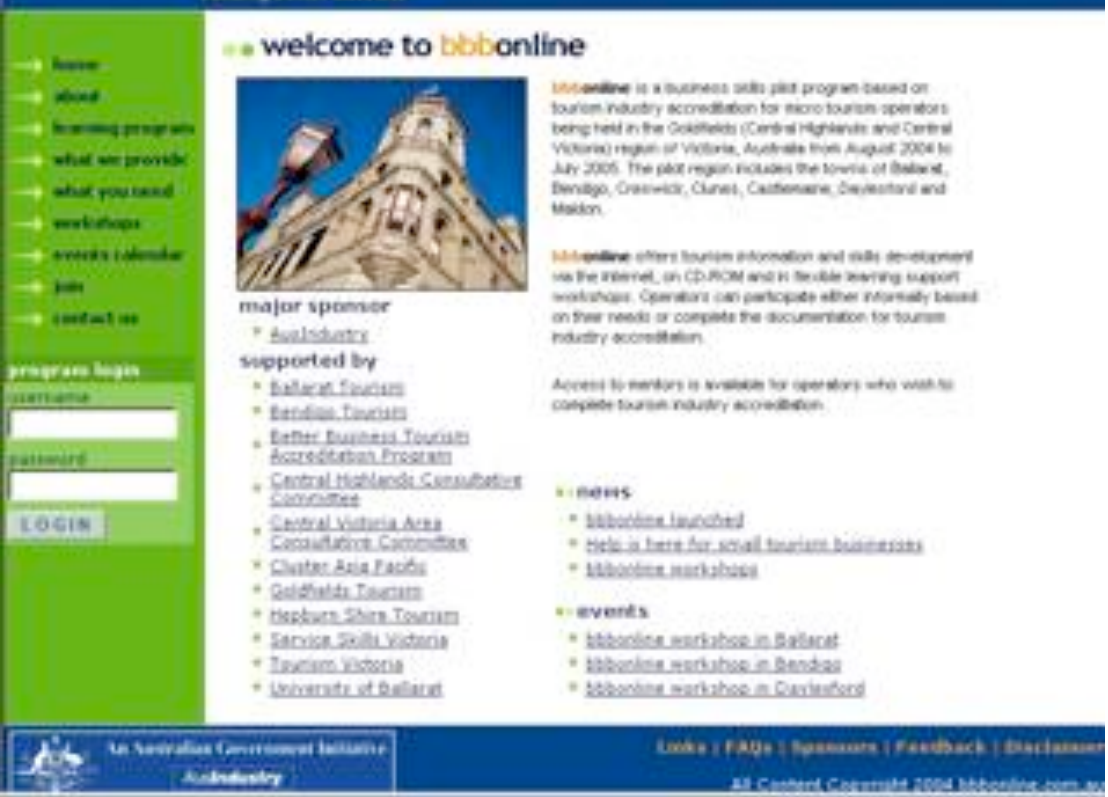

Figure 3. BBBOnline.com.au

\section{bbbonline}

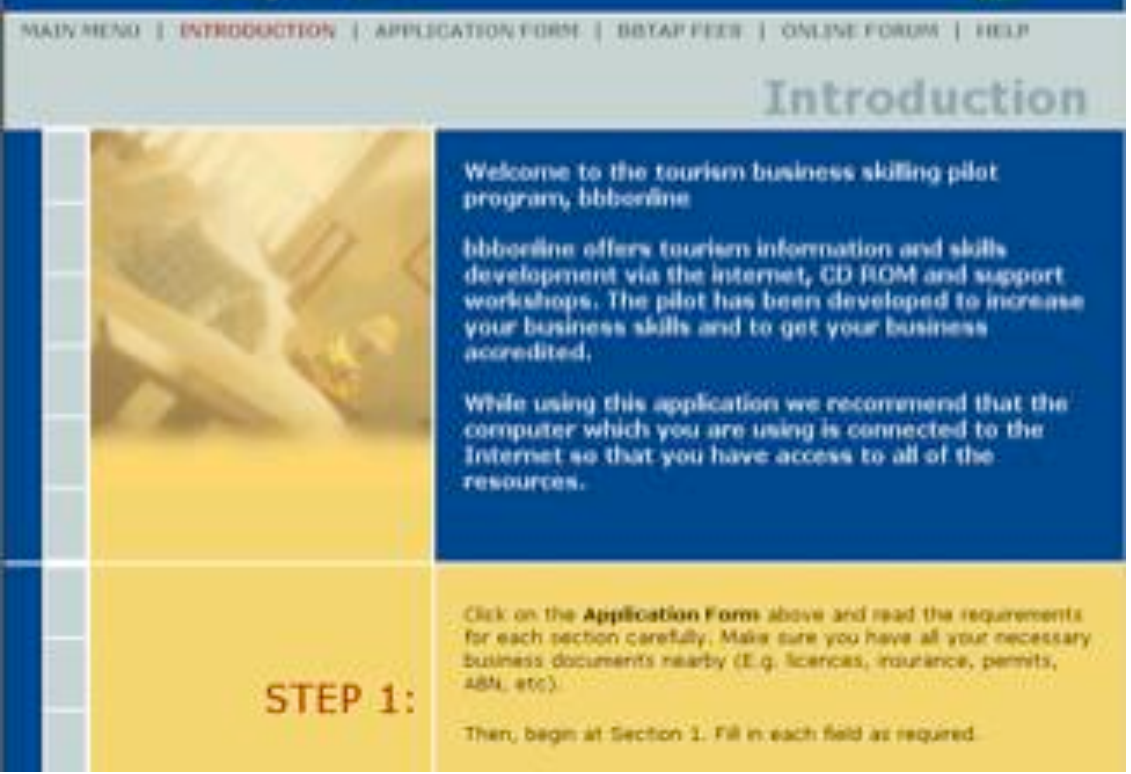

Figure 4. BBBOnline Tourism Business Skills Pilot Program

Figure 4 illustrates the introductory screen for the web-based version of the BBBOnline operator interface. The BBBOnline learning program supports operators preparing for self-accreditation by stepping them through modules which include: business details; business compliance; insurance; marketing and communications plan; customer service; business operating systems; human resource management; risk management; economic sustainability and financial systems; environmental sustainability; social and cultural sustainability; business plan; continuous improvement and code of conduct. Operators can readily access appropriate resources as they work through the learning program. These include more information, samples and web links. 
As the BBBOnline pilot project has moved from its planning to implementation phase project stakeholders have become increasingly aware of potential benefits of the delivery approach and infrastructure. Apart from identifying an opportunity to expand the service to meet the needs of tourism operators outside the accommodation sector (attractions; cellar door; tour operators and Visitor Information Centres) the potential for replication of similar functionality in a variety of learning contexts and across a range of business sectors has been identified.

The University's understanding of the critical issues for small and micro tourism operators and engagement with key stakeholder organisations during the planning, development and rollout of the BBBOnline project enhances the potential for ongoing training utilising the services developed through the pilot project. It is, however, unlikely that the UoB would have been able to provide this sectorspecific approach to training without access to the 'in house' expertise of CECC.

The ICT and Internet enhanced platform effectively links key stakeholders, operators, tourism industry managers and mentors while also supporting a variety of learning modes. For CECC, the BBBOnline project has provided an opportunity to connect with UoB academics in a more strategic and whole-of-institution way. It has also provided an opportunity to demonstrate how ICT can be used to enhance more traditional research and teaching activities in an area of regionally identified economic development priority.

\section{Conclusion}

Three very different case studies have been presented in this paper to demonstrate the important support role a university can play in the establishment and ongoing sustainability of regional ICT initiatives. A number of similarities are evident from the engagement approach demonstrated through the Wendouree West Community Renewal, Moorabool Online Community and the Building Better Business Online initiatives:

1. Opportunity identification - High levels of ICT expertise have been combined with a sound understanding of regional economic and social development priority. Active engagement with community members and a willingness to invest in preliminary consultation and research has been demonstrated as critical components of opportunity identification.

2. Resource attraction - Practical support has been provided through the identification and attraction of internal and external human, financial and infrastructure resources necessary to initially implement and then sustain initiatives.

3. Infrastructure development - In a variety of contexts (community, government, business) infrastructure has been developed to effectively and actively support end users in doing locally significant and empowering things with ICT.

4. Training and facilitation - Commitment to participatory design, action research, face-toface training, facilitation and ongoing support.

5. Evaluation and ongoing enhancement - Support provided to communities for evaluating initiative outcomes as a pathway to identifying opportunities for services to evolve and respond to new circumstance or opportunities.

CECC activities contribute positively to the UoB goal of providing leadership for the uptake of ICT in industries, local government and within and among regional groups. In the context of creating opportunities for the effective and active use of ICT, the case studies demonstrate that the UoB has made significant progress through a combination of on-the-ground leadership, infrastructure, collaboration and multi-disciplinary research. Universities can and in some instances already do play an important support role in the establishment and ongoing sustainability of regional ICT initiatives. 


\section{References}

Australian Bureau of Statistics (2003). 2001 Census of Population and Housing 2016.2 Selected Characteristics for Urban Centres and Localities: Victoria. Canberra, ABS.

Barlow, D. M. (1997). "Electronic Community Networks in Rural Australia: A Model for Social Development in the Information Society." Australian Social Work 50(1): 3-8.

Braun, P. and M. Hollick (2002). Small Business Enterprise Culture Program Capacity Building for Small and Micro Tourism Enterprises: Developing Sustainable Competitive Advantage. Ballarat, University of Ballarat.

Denison, T., G. Hardy, et al. (2002). Community Networks: Identities, Taxonomies and Evaluations. Electronic Networking 2002 - Building Community Conference, Monash University, Caulfield Campus, Melbourne, Centre for Community Networking Research School of Information Management \& Systems, Monash University.

Department for Information Technology and the Arts (1998). A Strategic Framework for the Information Economy: Identifying Priorities for Action. Canberra, Commonwealth of Australia.

Garlick, S. (2000). Engaging Universities and Regions: Knowledge Contribution to Regional Economic Development in Australia. Canberra, Evaluations and Investigations Programme Higher Education Division Department of Education, Training and Youth Affairs.

Hunter, A. (1999). Opportunities Through Communications Technology for Regional Australia. Regional Australia Summit, Canberra.

Information Policy Advisory Council (1997). Rural \& Regional.au/ for All. Canberra, Department of Communications and the Arts, Australia.

Institute for Regional and Rural Research (2003). Position Paper No. 4 Community/University Engagement through Research. Ballarat, University of Ballarat.

Multimedia Victoria (2002). Connecting Victoria: A Progress Report 1999-2002. Melbourne, State Government of Victoria.

Municipal Association of Victoria and ETC Electronic Trading Concepts Pty Ltd (2000). Local Government - Integrated Online Service Delivery Strategy and Implementation Plan, Executive Summary - Final. Melbourne, Municipal Association of Victoria.

National Office for the Information Economy (2001). B2B E-Commerce: Capturing Value Online. Canberra, Commonwealth of Australia.

National Office for the Information Economy (2002). The Benefits of Doing Business Electronically eBusiness. Canberra, Commonwealth Government. 2002.

National Office for the Information Economy (2002). Guide to Successful eBusiness Collaboration. Canberra, Commonwealth of Australia.

O'Neil, D. (2002). “Assessing Community Informatics: A Review of Methodological Approaches for Evaluating Community Networks and Community Technology Centres." Internet Research: Electronic Networking Applications and Policy 12(1): 76-102.

Porter, M. E. (2001). “Strategy After the Net.” BOSS(April 2001): 17-23.

Simpson, R. (1999). Brave New Regions. Regional Australia Summit, Canberra, Australia. 
Thompson, H. (2002). Final Report MainStreet.au.com Regional Portal Project. Ballarat, Centre for Electronic Commerce and Communications, University of Ballarat.

University of Ballarat (2002). Statement of Strategic Intent 2002-2004. Ballarat, University of Ballarat. 